\title{
The Alcohol Dehydrogenase Isoenzyme as a Potential Marker of Pancreatitis
}

\author{
WOJCIECH JELSKI ${ }^{1}$, JOANNA PIECHOTA ${ }^{2}$, KAROLINA ORYWAL $^{1}$ and MACIEJ SZMITKOWSKI ${ }^{1}$ \\ ${ }^{1}$ Department of Biochemical Diagnostics, Medical University, Bialystok, Poland; \\ ${ }^{2} 2$ nd Department of Obstetrics and Gynecology, Medical University of Warsaw, Warsaw, Poland
}

\begin{abstract}
Background/Aim: Human pancreas parenchyma contains various alcohol dehydrogenase $(A D H)$ isoenzymes and also possesses aldehyde dehydrogenase $(A L D H)$ activity. The altered activities of $A D H$ and $A L D H$ in damaged pancreatic tissue in the course of pancreatitis are reflected in the human serum. The aim of this study was to investigate a potential role of $A D H$ and $A L D H$ as markers for acute $(A P)$ and chronic pancreatitis $(C P)$. Patients and Methods: Serum samples were collected for routine biochemical investigations from 75 patients suffering from acute pancreatitis and 70 patients with chronic pancreatitis. Fluorometric methods were used to measure the activity of class I and II ADH and ALDH activity. The total ADH activity and activity of class III and IV isoenzymes were measured by a photometric method. Results: There was a significant increase in the activity of $A D H$ III isoenzyme (15.06 mU/l and $14.62 \mathrm{mU} / \mathrm{l} v \mathrm{~s} .11 .82 \mathrm{mU} / \mathrm{l} ; p<0.001)$ and total ADH activity (764 mU/l and $735 \mathrm{mU} / \mathrm{l}$ vs. $568 \mathrm{mU} / \mathrm{l})$ in the sera of patients with acute pancreatitis or chronic pancreatitis compared to the control. The diagnostic sensitivity for ADH III was about $84 \%$, specificity was $92 \%$, positive and negative predictive values were $93 \%$ and $87 \%$ respectively in acute pancreatitis. Area under the Receiver Operating Curve (ROC) curve for $A D H$ III in $A P$ and $C P$ was 0.88 and 0.86 respectively. Conclusion: $A D H$ III has a potential role as a marker of acute and chronic pancreatitis.
\end{abstract}

Chronic and acute pancreatitis is a disease of heterogenous etiology. Acute pancreatitis (AP) is associated with an increase in the activity of pancreatic enzymes in the pancreas parenchyma and body fluids, as well as dysfunction of many

Correspondence to: Wojciech Jelski, Department of Biochemical Diagnostics, Medical University, Waszyngtona 15 A, 15-269 Bialystok, Poland. Tel: +48 857468587, Fax: +48 857468585, e-mail: wjelski@umb.edu.pl

Key Words: Alcohol dehydrogenase isoenzymes, aldehyde dehydrogenase, acute pancreatitis, chronic pancreatitis. organs (1). Chronic pancreatitis (CP) is a neuroinflammatory process characterized by loss of both exocrine and endocrine functions. The disease may occur clinically either with a single symptom or a combination of symptoms associated with loss of function of the pancreas (2). AC is a disease with varying degrees of severity. Most patients have a relatively mild course and leave the hospital in less than seven days. Other patients will endure a complicated course and a long stay in the intensive care unit, as well as numerous diagnostic tests and therapeutic interventions that will sometimes result in death. (3). Chronic pancreatitis is characterized by irreversible damage developing progressively over time. Alcohol abuse, which accounts for $50-80 \%$ of inflammation of the pancreas, is the dominant cause, whereas other common etiologic factors include recurrent biliary disease, hemochromatosis and metabolic endocrine disorders (4). The pathogenesis of alcoholic pancreatitis remains to be fully explained, but there is evidence to support the concept that the metabolism of ethanol by pancreatic parenchyma and the consequent generation of toxic metabolites (e.g. acetaldehyde) can play an important role in the development of both chronic and acute pancreatic injury (5). The pancreas can metabolize ethanol by means of non-oxidative and oxidative pathways. The main oxidative enzyme system uses alcohol dehydrogenase (ADH) and aldehyde dehydrogenase (ALDH). Some studies have confirmed that alcohol dehydrogenase is present in pancreatic tissue and performs many different important physiological functions $(6,7)$. ADH includes a family of enzymes that are grouped in several classes (8). The comparison of alcohol dehydrogenase isoenzyme activities in the pancreas showed that there are four classes of isoenzymes. Among alcohol dehydrogenase isoenzymes the highest activity in the pancreas is represented by class III isoenzymes. The pancreas possesses also aldehyde dehydrogenase activity that catalyzes the metabolism of acetaldehyde to acetic acid (6).

The altered activities of enzymes in damaged pancreatic parenchyma in the course of pancreatitis are reflected in the serum. In our previous study, we showed that the total ADH 
activity was elevated in the sera of patients with chronic and acute pancreatitis. The increase in total ADH activity was correlated with ADH class III and appears to be due to the release of this isoenzyme from inflammatory cells of the pancreas (9).

In the present study, which is a continuation of our previous research, we defined the diagnostic criteria such as diagnostic specificity, sensitivity, predictive value for positive (PVPR) and negative results (PVNR), and receiveroperating characteristics (ROC) curve of tested enzymes. These data may be used to assess ADH and ALDH as candidates for markers of AP and CP.

\section{Patients and Methods}

Patients. The protocol was approved by the Human Care Committee of the Medical University in Bialystok, Poland (Approval Nr R-I002/25/2016). All patients gave informed consent for the examination.

Serum samples were collected for routine biochemical investigations from 75 patients suffering from acute pancreatitis (53 males and 22 females, mean age 46 years, range $=31-69$ years) and 70 patients with chronic pancreatitis (50 males and 20 females, mean age 53 years, range $=36-68$ years) hospitalized in the Department of Medicine and Gastroenterology, Regional Hospital of Bialystok. The group with acute pancreatitis included 44 patients with a mean alcohol intake greater than $20 \mathrm{~g} /$ day $(32 \mathrm{men})$ and $10 \mathrm{~g} /$ day (12 women). This group included also 31 patients $(21$ men and 10 women) who drank alcohol moderately (1 drinks/day on 5-6 days/week). The group of patients with chronic pancreatitis included 52 heavy drinkers (42 men, 10 women) and 18 moderate drinkers ( 8 men and 10 women). Serum samples were also obtained from 100 healthy subjects (control group, 65 males, 35 females, aged 30-68 years). The control group included 58 heavy drinkers (42 men, 16 women) and 42 moderate drinkers ( 23 men and 19 women). Control groups were selected from healthy community members who attend the hospitals for routine physical checkups at the Department of Preventive Medicine and heavy drinkers were recruited from patients admitted to the hospital for alcohol detoxification. All were volunteers and were identified as those with normal results in all physical and blood tests. Before the examinations the control group did not consume alcohol for one month and ethanol did not exist in the serum sample of any subject when it was collected.

Methods. Determination of total ADH activity. Total ADH activity was determined by the photometric method with p-nitrosodimethylaniline (NDMA) as a substrate (10). The reaction mixture (total vol. $2 \mathrm{ml}$ ) contained $1.8 \mathrm{ml}$ of a $26 \mathrm{mM}$ solution of substrate in $0.1 \mathrm{M}$ of sodium phosphate buffer ( $\mathrm{pH} 8.5$ ) and $0.1 \mathrm{ml}$ of a mixture containing $0.25 \mathrm{M}$ n-butanol, $5 \mathrm{mM}$ NAD and $0.1 \mathrm{ml}$ of serum. The reduction of NDMA was monitored at $440 \mathrm{~nm}$ on a Shimadzu UV/VIS 1202 spectrophotometer (Shimadzu Europa GmbH, Germany).

Determination of total ALDH activity. Aldehyde dehydrogenase activity was determined using the fluorogenic method based on the oxidation of 6-methoxy-2-naphtaldehyde to the fluorescent 6 -methoxy-2 naphtoate $(11,12)$. The reaction mixture contained $60 \mathrm{ml}$ of substrate, $2.8 \mathrm{ml}$ of $50 \mathrm{mM}$ sodium phosphate buffer
(pH 8.5), $20 \mathrm{ml}$ of $11.4 \mathrm{mM} \mathrm{NAD}$ and $60 \mathrm{ml}$ of serum. The fluorescence was read at excitation wavelength 310 and emission wavelength $360 \mathrm{~nm}$ on a Shimadzu RF-5301 spectrofluorophotometer (Shimadzu Europa GmbH, Germany).

Determination of class I and II ADH isoenzymes. Class I and II alcohol dehydrogenase isoenzyme activities were determined using fluorogenic substrates (4-methoxy-1-naphthaldehyde for class I and 6-methoxy-2-naphthaldehyde for class II) in a reduction reaction according to Wierzchowski et al. (13). The assays were performed in a reaction mixture containing substrate $(150 \mathrm{ml}$ of $300 \mathrm{mM})$, serum $(60 \mathrm{ml}), 0,1 \mathrm{M}$ of sodium phosphate buffer, $\mathrm{pH} 7.6(2.69 \mathrm{ml})$ and NADH $(100 \mathrm{ml}$ of $1 \mathrm{mM})$ in conditions previously described (14). The measurements were performed on a Shimadzu RF-5301 spectrofluorophotometer (Shimadzu Europa GmbH, Germany) at excitation wavelength $316 \mathrm{~nm}$ for both substrates and emission of $370 \mathrm{~nm}$ for ADH I and $360 \mathrm{~nm}$ for ADH II.

Determination of class III ADH isoenzyme. The assay mixture for ADH III activity contained $\mathrm{n}$-octanol as a substrate $(31 \mathrm{ml}$ of 1 $\mathrm{mM})$, serum $(100 \mathrm{ml})$, NAD $(240 \mathrm{ml}$ of $1.2 \mathrm{mM})$ in $0.1 \mathrm{M} \mathrm{NaOH}$ glycine buffer $(\mathrm{pH} 9,6)(15,16)$. The reduction of NAD was monitored at $340 \mathrm{~nm}$ and $37^{\circ} \mathrm{C}$ on a Shimadzu UV/VIS 1202 spectrophotometer.

Determination of class IVADH isoenzyme. The assay mixture for class IV of ADH activity contained $\mathrm{m}$-nitrobenzaldehyde as a substrate $(132 \mathrm{ml}$ of $80 \mathrm{mM})$, serum $(50 \mathrm{ml})$, NADH $(172 \mathrm{ml}$ of 86 $\mathrm{mM})$ in $0.1 \mathrm{M}$ sodium phosphate buffer $(\mathrm{pH} 7.5)(17,18)$. The oxidation of NADH was monitored at $340 \mathrm{~nm}$ and $37^{\circ} \mathrm{C}$ on a Shimadzu UV/VIS 1202 spectrophotometer.

Diagnostic values calculation. The diagnostic criteria, such as the diagnostic sensitivity, specificity, predictive and negative value and the ROC curve, were determined using the GraphRoc Program for Windows (University of Turku, Turku, Finland) and the following equations (19)

\begin{tabular}{|c|c|c|}
\hline \multirow{2}{*}{ Sensitivity } & number of true-positive results & \multirow{2}{*}{$\times 100 \%$} \\
\hline & $\begin{array}{l}\text { number of true-positive results }+ \\
\text { number of false-negative results }\end{array}$ & \\
\hline \multirow{2}{*}{ Specificity } & number of true-negative results & \multirow{3}{*}{$\times 100 \%$} \\
\hline & $\begin{array}{c}\text { number of true-negative results }+ \\
\text { number of false-positive results }\end{array}$ & \\
\hline \multirow{2}{*}{ PVPR = } & number of true-positive results & \\
\hline & $\begin{array}{l}\text { number of true-positive }+ \\
\text { number of false-positive results results }\end{array}$ & \multirow{2}{*}{$\times 100 \%$} \\
\hline \multirow{2}{*}{ PVNR = } & number of true-negative results & \\
\hline & nber of false-negative results $r$ & $\times 100 \%$ \\
\hline
\end{tabular}

Statistical analysis. A preliminary statistical analysis (Chi-square test) revealed that the distribution of ADH and ALDH activities did 
Table I. ADH and ALDH activities in sera of patients with acute and chronic pancreatitis.

\begin{tabular}{|c|c|c|c|c|c|c|}
\hline $\begin{array}{l}\text { Tested } \\
\text { group }\end{array}$ & $\begin{array}{l}\text { ADH I } \\
\text { Median } \\
\text { Range } \\
\text { Mean }\end{array}$ & $\begin{array}{l}\text { ADH II } \\
\text { Median } \\
\text { Range } \\
\text { Mean }\end{array}$ & $\begin{array}{l}\text { ADH III } \\
\text { Median } \\
\text { Range } \\
\text { Mean }\end{array}$ & $\begin{array}{c}\text { ADH IV } \\
\text { Median } \\
\text { Range } \\
\text { Mean }\end{array}$ & $\begin{array}{c}\text { ADH Total } \\
\text { Median } \\
\text { Range } \\
\text { Mean }\end{array}$ & $\begin{array}{l}\text { ALDH Total } \\
\text { Median } \\
\text { Range } \\
\text { Mean }\end{array}$ \\
\hline $\begin{array}{l}\text { Acute pancreatitis } \\
(\mathrm{n}=75)\end{array}$ & $\begin{array}{c}2.943 \\
1.185-5.815 \\
2.877\end{array}$ & $\begin{array}{c}14.28 \\
5.83-21.25 \\
13.86\end{array}$ & $\begin{array}{c}15.06 \\
8.40-23.16 \\
14.38\end{array}$ & $\begin{array}{c}5.25 \\
2.46-11.87 \\
5.01\end{array}$ & $\begin{array}{c}764 \\
296-1604 \\
712\end{array}$ & $\begin{array}{c}2.946 \\
1.446-6.317 \\
2.896\end{array}$ \\
\hline $\begin{array}{l}\text { Chronic pancreatitis } \\
(\mathrm{n}=70)\end{array}$ & $\begin{array}{c}2.911 \\
1.055-5.648 \\
2.823\end{array}$ & $\begin{array}{c}14.17 \\
7.02-19.69 \\
13.65\end{array}$ & $\begin{array}{c}14.62 \\
8.02-21.45 \\
14.17\end{array}$ & $\begin{array}{c}5.11 \\
2.21-11.03 \\
4.93\end{array}$ & $\begin{array}{c}735 \\
275-1548 \\
685\end{array}$ & $\begin{array}{c}2.907 \\
1.415-6.198 \\
2.855\end{array}$ \\
\hline $\begin{array}{l}\text { Control } \\
(n=100)\end{array}$ & $\begin{array}{c}2.848 \\
1.021-5.477 \\
2.795 \\
p^{\mathrm{a}}=0.366 \\
p^{\mathrm{b}}=0.414 \\
p^{\mathrm{c}}=0.385\end{array}$ & $\begin{array}{c}13.96 \\
5.24-18.91 \\
13.48 \\
p^{\mathrm{a}}=0.514 \\
p^{\mathrm{b}}=0.537 \\
p^{\mathrm{c}}=0.404\end{array}$ & $\begin{array}{c}11.82 \\
7.15-18.73 \\
10.96 \\
p^{\mathrm{a}}<0.001^{*} \\
p^{\mathrm{b}}<0.001^{*} \\
p^{\mathrm{c}}=0.263\end{array}$ & $\begin{array}{c}4.94 \\
2.16-11.22 \\
4.75 \\
p^{\mathrm{a}}=0.482 \\
p^{\mathrm{b}}=0.515 \\
p^{\mathrm{c}}=0.433\end{array}$ & $\begin{array}{c}568 \\
231-1290 \\
515 \\
p^{\mathrm{a}}<0.001^{*} \\
p^{\mathrm{b}}<0.001^{*} \\
p^{\mathrm{c}}=0.311\end{array}$ & $\begin{array}{c}2.865 \\
1.368-6.124 \\
2.814 \\
p^{\mathrm{a}}=0.536 \\
p^{\mathrm{b}}=0.365 \\
p^{\mathrm{c}}=0.248\end{array}$ \\
\hline
\end{tabular}

Data are expressed as mU/l. *Statistically significant differences between suitable groups; $p^{\mathrm{a}}$ : acute pancreatitis $v s$. control; $p^{\mathrm{b}}$ : chronic pancreatitis $v s$. control; $p^{\mathrm{c}}$ : acute pancreatitis $v s$. chronic pancreatitis.

Table II. Diagnostic criteria for ADH total and ADH III for acute and chronic pancreatitis.

\begin{tabular}{lccccc}
\hline $\begin{array}{l}\text { Tested } \\
\text { enzymes }\end{array}$ & $\begin{array}{c}\text { Cut-off } \\
\mathrm{mU} / \mathrm{l}\end{array}$ & $\begin{array}{c}\text { Diagnostic } \\
\text { sensitivity } \\
(\%)\end{array}$ & $\begin{array}{c}\text { Diagnostic } \\
\text { specificity } \\
(\%)\end{array}$ & $\begin{array}{c}\text { Predictive value } \\
\text { for positive results } \\
(\%)\end{array}$ & $\begin{array}{c}\text { Predictive value } \\
\text { for negative results } \\
(\%)\end{array}$ \\
\hline $\begin{array}{l}\text { Acute pancreatitis } \\
\text { ADH total }\end{array}$ & 1250 & 76 & & 85 & 82 \\
ADH III & 17.54 & 84 & 80 & 93 & 87 \\
Chronic pancreatitis & 1190 & 73 & 78 & 84 & 81 \\
ADH total & 17.10 & 83 & 91 & 92 & 86 \\
ADH III & & & & 82 \\
\hline
\end{tabular}

The cut-off points were obtained from a study of a healthy population (95th percentile).

not follow a normal distribution. Consequently, the Wilcoxon's test was used for statistical analysis. Data were presented as median, range and mean values. Statistically significant differences were defined as comparisons resulting in $p<0.05$.

\section{Results}

The activities of alcohol dehydrogenase, aldehyde dehydrogenase and isoenzymes of alcohol dehydrogenase in the sera are shown in Table I. The activity of ADH III in the acute pancreatitis and chronic pancreatitis group increased about 27\% (15.06 mU/l) and 24\% (14.62 mU/l), respectively, in comparison to the healthy subjects $(11.82 \mathrm{mU} / 1)$. This increase was statistically significant $(p<0.001)$. The other tested classes of ADH isoenzymes had higher activities in the serum of patients with pancreatitis, but the differences were not statistically significant in all patient groups $(p>0.05)$. The total activity of ADH was significantly higher in patients with AP and CP than in controls (26 and $23 \%$ respectively). The total activity of $\mathrm{ADH}$ was $764 \mathrm{mU} / 1$ in patients with acute pancreatitis, $734 \mathrm{mU} / 1$ in chronic disease and $568 \mathrm{mU} / 1$ in the control group. The analysis of ALDH activity did not indicate a significant difference between tested groups and healthy subjects.

The analysis of ADH, ALDH and ADH isoenzymes activities in the serum did not indicate significant differences between patients with acute pancreatitis and chronic pancreatitis.

Table II shows the diagnostic criteria for total ADH and ADH III. The sensitivity ( $84 \%$ in acute pancreatitis and $83 \%$ in chronic pancreatitis) and specificity (92\% in AP and $91 \%$ in $\mathrm{CP}$ ) of $\mathrm{ADH}$ III were higher than values of the total ADH. Both the predictive value for positive results and the 

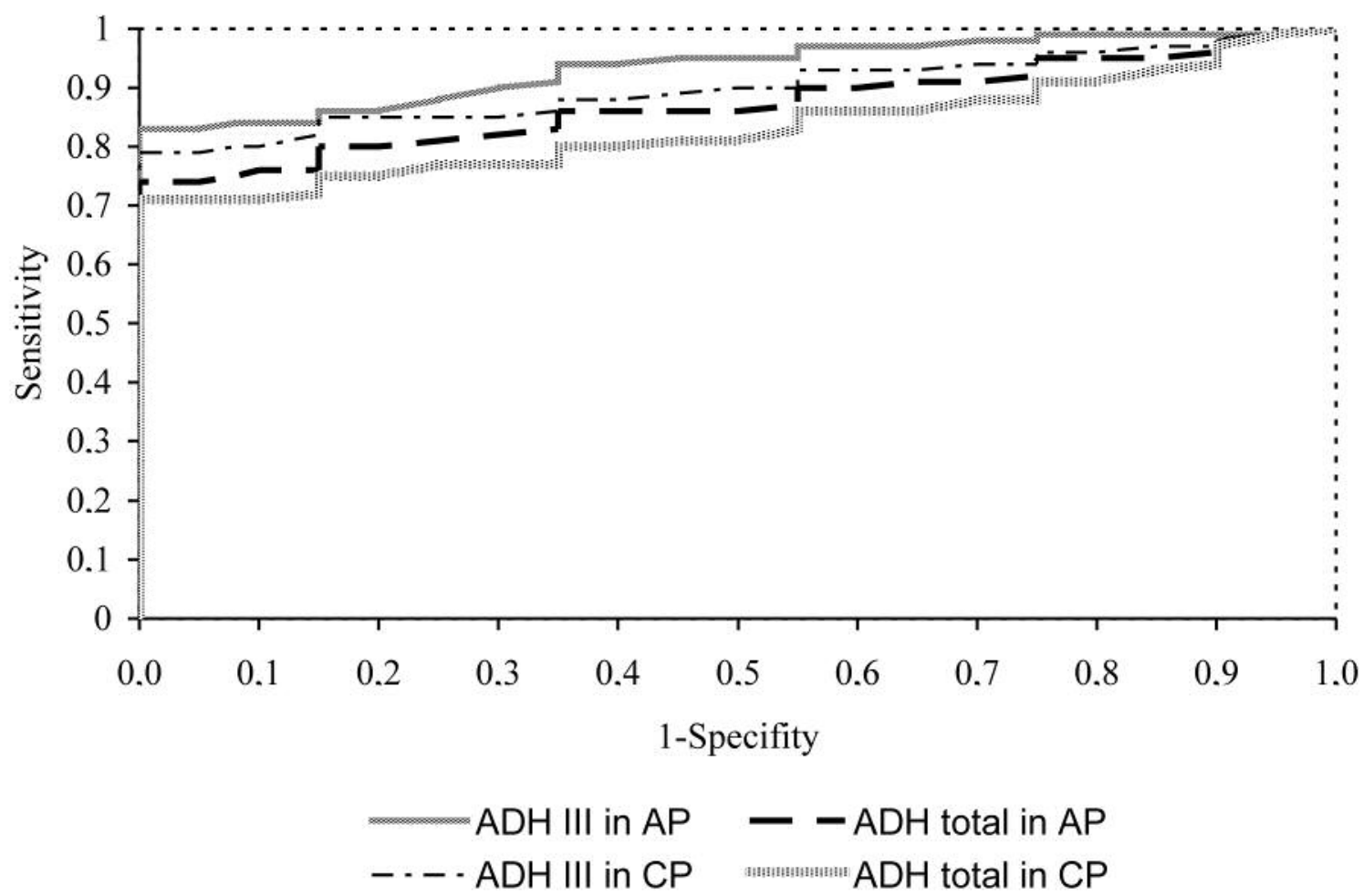

Figure 1. Areas under ROC curves for ADH III and ADH total in acute pancreatitis and chronic pancreatitis. ADH III in AP, Area=0.8846, $S E=0.0368 ; A D H$ total in AP, Area=0.8268, $S E=0.0493 ; A D H$ III in CP, Area=0.8659, SE=0.0487; ADH total in CP, Area=0.8046, $S E=0.0334$.

predictive value for negative results were also the highest for the class III of alcohol dehydrogenase isoenzymes in patients with pancreatitis. PVPR and PVNR for ADH III in patients with AP were $93 \%$ and $87 \%$ respectively and in patients with CP were $92 \%$ and $86 \%$.

The relationship between diagnostic sensitivity and specificity was illustrated by a ROC curve (Figure 1). It shows that the area under the ROC curve of ADH III (0.88 in $\mathrm{AP}$ and 0.86 in $\mathrm{CP}$ ) was higher than the ROC area of $\mathrm{ADH}$ total (0.82 in AP and 0.80 in $\mathrm{CP})$.

\section{Discussion}

Pancreatitis is a serious complication of alcohol abuse. It shows histopathological spectrum from acute necroinflammation of the gland (acute pancreatitis) to chronic irreversible destruction of the structure and/or function of the pancreas (chronic pancreatitis) (5). The pathogenesis of pancreatitis remains poorly understood despite the demonstration that ethanol intake induces many alterations in pancreatic parenchyma (20). Ethanol toxicity mechanisms have been most extensively studied in liver cells, and metabolism of alcohol by hepatocytes plays a crucial role in the pathogenesis of alcoholic liver disease
(ALD) (21). In contrast, ethanol metabolism in pancreas has received less attention. The pancreas can metabolize alcohol via both nonoxidative and oxidative pathways yielding the toxic metabolites fatty acids ethyl esters (FAEEs) and acetaldehyde, respectively (7). Some studies have suggested that alcohol-induced pancreatic injury may be mediated by the ethanol toxic metabolites $(22,23)$.

Pancreatitis leads to hypoxia - the secondary phenomenon that results from a decreased blood supply to the pancreas. This, in turn causes dysfunction of intracellular organelles and increases the permeability of cell membranes. In pancreatitis, enzymes play function by inducing the production of cytokines, stimulating an inflammatory response, pancreas autodigestion, and in consequence development of multiorgan failure (24). The altered enzyme activity in damaged pancreatic parenchyma is reflected in the serum. For example, the total ADH activity in the serum of patients is elevated in the course of both acute and chronic pancreatitis. The increase of total alcohol dehydrogenase is positively correlated with $\mathrm{ADH}$ III isoenzymes and therefore the reason for the increase of total ADH during pancreatitis is the elevation of class III $\mathrm{ADH}$ isoenzymes. A significant increase of $\mathrm{ADH}$ III in the serum of patients can be explained by the fact that this isoenzyme has the highest activity among all $\mathrm{ADH}$ in the 
pancreatic tissue and seems to be caused by its secretion from damaged cells of pancreas (9). These observations are similar to that of pancreatic cancer. In our previous studies we have found that the total activity of $\mathrm{ADH}$ and the class III ADH were significantly higher in pancreatic cancer tissue than in healthy cells of pancreas. For this reason, the activity of ADH III was significantly elevated in the sera of patients with pancreatic cancer $(25,26)$.

Patients with pancreatitis require early initiation of intensive treatment. However, in practice, early identification of these patients is an unresolved problem. Clinical scores such as Glasgow, Ranson or Acute Physiology and Chronic Health Evaluation II (APACHE II) as well as C-reactive protein (CRP) measurements that are routinely used for this purpose, provide a reliable diagnosis after 48 hours from the onset of pancreatitis (3). According to the revised Atlanta classification, pancreatitis can be diagnosed if at least two of the following three criteria are met: abdominal pain (acute onset of persistent and severe epigastric pain, often radiating to the back), serum lipase or amylase activity at least three to four times the upper normal limit (27). Diagnostic imaging is necessary in patients with a slight elevation of the enzyme. Importantly, pancreatic enzyme activities at the time of hospital admission are not associated with severity of the disease. In addition to serum lipase and amylase, the following variables should be established on admission: concentrations of electrolytes, creatinine, blood urea nitrogen, blood sugar, serum alanine, aspartate transaminase and alkaline phosphatase, complete blood count without differential, coagulation status (28).

In the present study we assessed whether the activity of alcohol dehydrogenase or aldehyde dehydrogenase could be a biomarker of pancreatitis and to relevant for diagnosis. Due to the risk and limitations of a pancreatic biopsy, the current diagnostic paradigm for pancreatitis is based on crosssectional imaging studies for detection of well-established morphologic changes of disease, and pancreatic function tests to detect exocrine pancreatic insufficiency. These diagnostic methods are specific to pancreatitis, but probably lack the sensitivity to detect early stages of the disease (29). The ideal marker should possess very high sensitivity, i.e. can be detected very early in the disease progression and have very high specificity, i.e. should not be detectable in healthy subjects. The criteria for $100 \%$ specificity and $100 \%$ sensitivity have not yet been fulfilled by any of the known diagnostic markers. In our present paper we have shown that during the course of acute and chronic pancreatitis diagnostic sensitivity was highest for ADH III (about 83-84\%) and $\mathrm{ADH}$ total (76\% in $\mathrm{AC}$ and 73 in $\mathrm{CP}$ ).

The predictive value for positive results indicates the probability by which a tumor exists in the case of positive test results. The negative predictive value for negative results predicts the probability that there is no tumor in the case of negative test results. In this study, ADH III has high predictive values for positive and negative results (92-93\% and $86-87 \%$ respectively). The most important criterion for disease markers is the sensitivity/specificity diagram - the ROC curve. The area under the ROC curve indicates the clinical suitability of the tested substances. The larger the area under the ROC curve corresponds to a better marker of the disease. In this study the ADH III area under the ROC curve was higher than that of total alcohol dehydrogenase.

The results in this paper are consistent with other studies performed on the pancreas (25). Our previous study demonstrated the potential importance of class III alcohol dehydrogenase isoenzyme as a marker of pancreatic cancer. The diagnostic criteria for ADH III are slightly lower for pancreatic cancer than for acute or chronic pancreatitis. The sensitivity and specificity of class III alcohol dehydrogenase isoenzyme in pancreatic cancer patients was $70 \%$ and $76 \%$, respectively (30).

This is the first study examining all the diagnostic criteria for alcohol dehydrogenase and aldehyde dehydrogenase in patients with acute or chronic pancreatitis. The obtained results indicate the potential clinical role of ADH (especially ADH III) as markers for pancreatitis.

\section{References}

1 Halonen KI, Pettila V, Leppaniemi AK, Kemppainen EA, Puolakkainen PA and Haapiainen RK: Multiple organ dysfunction associated with severe acute pancreatitis. Crit Care Med 30: 1274-1279, 2002.

2 Kleeff J, Friess H, Korc $M$ and Buchler MV: Chronic pancreatitis: pathogenesis and molecular aspects. Ann Ital Chir 71: 3-10, 2000.

3 Banks PA, Bollen TL, Dervenis C, Gooszen HG, Johnson CD, Sarr MG, Tsiotos GG and Vege SS: Classification of acutepancreatitis-2012: revision of the Atlanta classification and definitions by international consensus. Gut 62: 102-111, 2013.

4 Witt H, Apte MV, Keim V and Wilson JS: Chronic pancreatitis: challenges and advances in pathogenesis, genetics, diagnosis, and therapy. Gastroenterology 32: 1557-1573, 2007.

5 Wilson J and Apte MV: Role of alcohol metabolism in alcoholic pancreatitis. Pancreas 27: 311-315, 2003.

6 Chrostek L, Jelski W, Szmitkowski M and Puchalski Z: Alcohol dehydrogenase $(\mathrm{ADH})$ isoenzymes and aldehyde dehydrogenase $(\mathrm{ALDH})$ activity in the human pancreas. Dig Dis Sci 48: 12301233, 2003

7 Haber PS, Apte MV, Applegate TL, Norton ID, Korsten MA and Pirola RC: Metabolism of ethanol by rat pancreatic acinar cells. J Lab Clin Med 132: 294-302, 1998.

8 Riveros-Rosas H, Julian-Sanchez A and Pina E: Enzymology of ethanol and acetaldehyde metabolism in mammals. Arch Med Res 28: 453-471, 1997.

9 Jelski W, Kutylowska E, Laniewska-Dunaj M, Orywal K, Laszewicz W and Szmitkowski M: Alcohol dehydrogenase (ADH) isoenzymes and aldehyde dehydrogenase (ALDH) activity in the sera of patients with acute and chronic pancreatitis. Exp Mol Path 91: 631-635, 2011. 
10 Skursky L, Kovar J and Stachova M: A sensitive assay for alcohol dehydrogenase activity in blood serum. Anal Biochem 89: 65-71, 1979.

11 Jelski W, Kozlowski M, Laudanski J, Niklinski J and Szmitkowski M: The activity of class I, II, III and IV alcohol dehydrogenase $(\mathrm{ADH})$ isoenzymes and aldehyde dehydrogenase (ALDH) in esophageal cancer. Dig Dis Sci 54: 725-730, 2009.

12 Orywal K, Jelski W, Werel $\mathrm{T}$ and Szmitkowski M: The diagnostic significance of serum alcohol dehydrogenase isoenzymes and aldehyde dehydrogenase activity in prostate cancer patients. Anticancer Res 37: 4961-4965, 2017.

13 Wierzchowski J, Dafeldecker WP, Holmquist B and Vallee BL: Fluorimetric assay for isozymes of human alcohol dehydrogenase. Anal Biochem 178: 57-62, 1989.

14 Koivusalo M, Baumann M and Uotila L: Evidence for the identity of glutathione-dependent formaldehyde dehydrogenase and class III alcohol dehydrogenase. FEBS Lett 257: 105-109, 1989.

15 Dohmen K, Baraona E, Ishibashi H, Pozzato G, Moretti M and Matsunaga $\mathrm{C}$ : Ethnic differences in gastric $\sigma$-alcohol dehydrogenase activity and ethanol first pass metabolism. Alcohol Clin Exp Res 20: 1569-1576, 1996.

16 Orywal K, Jelski W, Werel $\mathrm{T}$ and Szmitkowski M: The diagnostic significance of serum alcohol dehydrogenase isoenzymes and aldehyde dehydrogenase activity in urinary bladder cancer patients. Anticancer Res 37: 3537-3541, 2017.

17 Jelski W, Chrostek L, Markiewicz W and Szmitkowski M: The activity of alcohol dehydrogenase (ADH) isoenzymes and aldehyde dehydrogenase (ALDH) in the sera of patients with breast cancer. J Clin Lab Anal 20: 105-108, 2006.

18 Orywal K, Jelski W, Zdrodowski M and Szmitkowski M: The diagnostic value of alcohol dehydrogenase isoenzymes and aldehyde dehydrogenase measurement sera of cervical cancer patients. Anticancer Res 36: 2265-2269, 2016.

19 Kairisto V, Virtanen A, Uusipaikka E, Voipio-Pulkki LM, Nanto $\mathrm{V}$ and Peltola O: Method for determining reference changes from patients' serial data: example of cardiac enzymes. Clin Chem 39: 2298-2304, 1993.
20 Pandol SJ and Raraty M: Pathobiology of alcoholic pancreatitis. Pancreatology 7: 105-114, 2007.

21 Lieber CS: Metabolism of alcohol. Clin Liver Dis 9: 1-35, 2005.

22 Werner J, Saghir M, Fernandez-del Castillo C, Warshaw AL and Laposata M: Linkage of oxidative and nonoxidative ethanol metabolism in the pancreas and toxicity of nonoxidative ethanol metabolites for pancreatic acinar cells. Surgery 129: 736-744, 2001.

23 Apte M, Pirola R and Wilson J: Mechanisms of alcoholic pancreatitis. J Gastr Hepat 25: 1816-1826, 2010.

24 Braganza JM, Lee SH, McCloy RF and McMahon MJ: Chronic pancreatitis. Lancet 377: 1184-1197, 2011.

25 Jelski W, Chrostek L and Szmitkowski M: The activity of class I, II, III and IV alcohol dehydrogenase isoenzymes and aldehyde dehydrogenase in the pancreatic cancer. Pancreas 35: 142-146, 2007.

26 Jelski W, Zalewski B and Szmitkowski M: Alcohol dehydrogenase (ADH) isoenzymes and aldehyde dehydrogenase (ALDH) activity in the sera of patients with pancreatic cancer. Dig Dis Sci 53: 2276-2280, 2008.

27 Lankisch PG, Burchard-Reckert S and Lehnick D: Underestimation of acute pancreatitis: patients with only a small increase in amylase/lipase levels can also have or develop severe acute pancreatitis. Gut 44: 542-544, 1999.

28 Chauhan S and Forsmark CE: The difficulty in predicting outcome in acute pancreatitis. Am J Gastroenterol 105: 443-445, 2010.

29 Banks PA and Freeman ML: Practice guidelines in acute pancreatitis. Am J Gastroenterol 101: 2379-2400, 2006.

30 Jelski W, Kutylowska E, Laniewska-Dunaj M and Szmitkowski $\mathrm{M}$ : Alcohol dehydrogenase (ADH) and aldehyde dehydrpgenase $(\mathrm{ALDH})$ as candidates for tumor markers in patients with pancreatic cancer. J Gastroenterol Liver Dis 20: 255-259, 2011.

Received February 19, 2018

Revised March 13, 2018

Accepted March 14, 2018 